\title{
BALDUÍNO RAMBO, S. J. E O COMECO DA ANTROPOLOGIA NA UFRGS
}

\author{
Pedro Ignácio Schmitz \\ Instituto Anchietano de Pesquisas, Universidade do Vale do Rio dos Sinos-Brasil
}

Resumo: Este texto é um testemunho sobre a vida e obra de Balduíno Rambo em particular no que se refere ao início da disciplina de Antropologia na UFRGS. O relato aborda a origem, formação, personalidade e o conjunto de suas atividades situando e contextualizando sua contribuição em diversas áreas do conhecimento.

Abstract: This article serves to witness the life and works of Balduíno Rambo, and his contribution to the the first clays of Anthropology at the Federal University of Rio Grande do Sul. Our material considers the origin, intellectual formation, personality, and activities of this thinker, situating his contributions to diverse fields of knowledge within the context of his time.

\section{Introdução}

O testemunho, que deixo, faz parte da memoria da disciplina de Antropologia que, a partir de um começo pouco expressivo, escolheu seus caminhos, se afirmou e pode hoje olhar para frente sem vergonha da identidade que assumiu.

Hoje o Departamento de Antropologia reúne um grupo seleto de professores, a maior parte com treinamento pós-graduado em países de Primeiro Mundo. As numerosas disciplinas, que oferece, a nível de graduação, são buscadas por alunos de variados cursos da Universidade. O programa de pós-graduação, a nível de Mestrado e Doutorado, não forma apenas cientistas sociais, mas é escolhido por outros profissionais, necessitados de enfoques humanos para seu trabalho. Os professores estão incorporados na universidade em tempo integral e dedicação exclusiva, desenvolvendo projetos de pesquisa, têm laboratórios bem montados e são atuantes na comunidade antropológica nacional e internacional. Os alunos participam dos projetos dos professores e têm acesso a treinamento teórico e metodológico desde o início da graduação até o término de seu doutorado. 


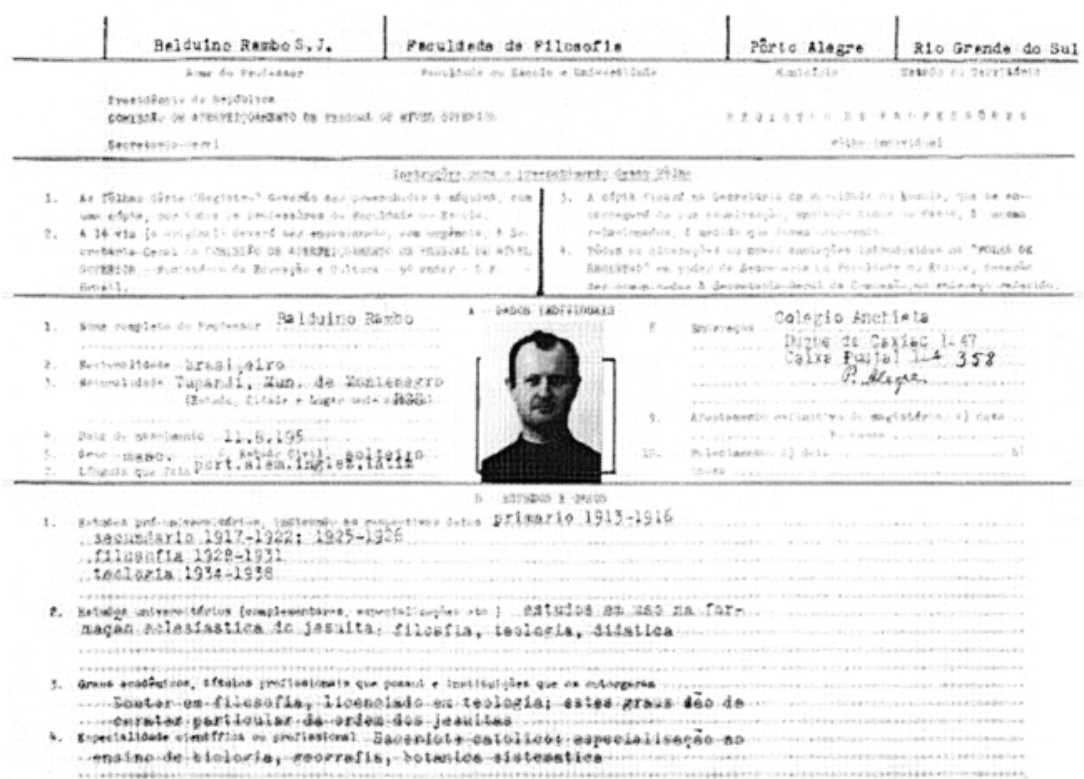

Ficha funcional do padre Balduíno Rambo S. J. arquivo projeto História da Antropologia no RS - UFRGS.

O começo do setor de Antropologia recua a 1943, inícios da Faculdade de Filosofia da URGS. Naquele tempo havia uma cadeira de Antropologia e Etnografia, com disciplinas de Antropologia Biológica e disciplinas de Etnografia e Etnologia, geral e do Brasil. Responsável pela cadeira era o Pe. Balduíno Rambo, S. J., que tinha como auxiliar para as disciplinas de Antropologia o Prof. Petrucci. Nem um, nem outro, tinham nas atividades universitárias sua ocupação principal, mas as aulas eram mais uma atividade ao lado de (muitas) outras. Nem um, nem outro, tinham recebido treinamento no setor, mas eram autodidatas. Ainda não havia, localmente, pessoas treinadas em Antropologia. Não podemos esquecer que os programas de pós-graduação foram implantados, no país, muito mais tarde e o doutorado no exterior não era muito acessível. As atividades com os alunos se restringiam às aulas, de caráter predominantemente informativo, e se destinavam a futuros professores de História e Geografia. Havia algum material ilustrativo, num pequeno museu, mas nenhuma pesquisa.

De 1943 a 1958 Rambo dava sozinho as aulas de Etnografia. Nesta última data ele me convidou a colaborar. Logo convidou também a seu irmão mais novo, Artur Blásio. Após o seu falecimento, em 11 de setembro de 1961, outros professores foram admitidos. 
Balduíno Rambo é da primeira leva de professores da Faculdade de Filosofia da URGS e o que recordo dele poderia ser aplicado, com as devidas adaptações, a outros professores deste período da instituição.

Devido ao que falei acima, a respeito dos professores do período, não teria sentido recordar apenas as atividades de Rambo na Universidade. Elas se tornam mais compreensíveis quando olhamos sua origem, formação, personalidade, o conjunto de suas atividades, sua representatividade na sociedade e as pessoas que formaram o núcleo da Faculdade de Filosofia da URGS.

Mas antes é preciso que apresente minhas credenciais para falar sobre Rambo. Ele foi meu professor quando cursei Geografia e História na URGS, de 1955 a 1958. De 1958 a 1961 fui seu colaborador na cadeira. Após a sua morte respondi pela mesma. De 1955 a 1961 convivi com ele debaixo do mesmo teto, na comunidade jesuítica do Colégio Anchieta, onde comecei minha carreira de professor. Nos últimos anos de sua vida fui seu secretário e amigo. Ele confiava em mim como um de seus sucessores.

\section{Origem e formação}

Balduíno Rambo nasceu em 11 de agosto de 1905, em Tupandi, RS, como primogênito de 11 irmãos, numa família de pequenos agricultores. Fez seus estudos iniciais no seminário dos jesuítas em São Leopoldo, RS. Em 1923 entrou no noviciado da Companhia de Jesus, em Pareci Novo, RS. Ali, como jovem jesuíta, fez dois anos de estudos clássicos e retórica, após o que lecionou dois anos no Colégio Catarinense, em Florianópolis. Depois deste primeiro intervalo nos estudos foi encaminhado pelos superiores para uma faculdade de Filosofia mantida pela Ordem perto de Munique, Alemanha, oportunidade em que tomou contato com a ciência européia e firmou seu interesse, já demonstrado desde a adolescência, pela Botânica. Concluída a faculdade de Filosofia era seu interesse continuar estudos na Europa, mas os superiores precisavam dele como professor no Colégio Anchieta, em Porto Alegre, RS, onde ficou mais dois anos. De 1934 a 1938 estudou Teologia em São Leopoldo e, em 31 de outubro de 1936, se ordenou sacerdote.

Concluídos os estudos voltou para o Colégio Anchieta, então tradicional educandário e centro de cultura de sua Ordem. Durante os 22 anos que ali viveu, deu aulas de História Natural no colégio, Etnografia na URGS, trabalhou na Secretaria de Educação e Cultura do Estado, realizou pesquisas em Botânica e Geografia, publicou livros e artigos científicos, didáticos e populares, escreveu poesias e cantos, dirigiu revistas e foi um sacerdote muito ativo e popular. Rambo 
era uma personalidade lúcida, disciplinada e trabalhadora. Tinha domínio de numerosas línguas e conhecimento enciclopédico não superficial. Mantinha intenso contato, pelo mundo, com personalidades ligadas a seus campos de interesse e atividade. Sua morte ocorreu em 11 de setembro de 1961, em plena atividade, em consequência de derrame cerebral, quando tinha 56 anos de idade.

\section{Principais atividades}

Entre as numerosas atividades é difícil dizer, em poucas palavras, onde fazia maior investimento.

Talvez na Botânica tenha deixado a obra mais duradoura. O interesse nesse estudo começou na adolescência, no seminário. A consolidação foi durante os três anos de estudos de Filosofia em Munique, onde apreendeu o modelo de trabalho científico. Durante os estudos de Teologia organizou um programa de estudos das plantas do Rio Grande do Sul, no qual diversos colegas jesuítas participaram, desenvolvendo cada um deles um grupo de famílias. A ele couberam as plantas com flores (os fanerógamos). Para cumprir a sua parte percorreu o Estado, colhendo, por regiões, amostras do maior número possível de plantas de seu setor. Assim reuniu aproximadamente 65.000 amostras em seu herbário, 54 publicações resultaram desse estudo, mas correspondem apenas ao começo da obra planejada. Calculava que, em mais 20 anos, de publicações frenéticas, publicaria o material recolhido. Sistemática, fitogeografia, evolução e história das plantas eram os temas preferidos. Seu herbário forma hoje o maior acervo e base do herbário do Instituto Anchietano de Pesquisas, onde as coleções dos outros membros do grupo de trabalho também foram depositadas e são estudadas.

Muito próximo de seu estudo de plantas nativas era seu interesse pela Geografia. Numa época em que as fotos aéreas ainda não cobriam o Brasil e não havia imagens de satélites, ele sobrevoou o Rio Grande do Sul e grandes extensões do resto do Brasil para o estudo de sua paisagem. Eram voos temerários, em pequenos aviões muito inseguros, mas que deram como resultado novos livros e mais artigos. O mais importante, recentemente reimpresso pela Unisinos, é a Fisionomia do Rio Grande do Sul (Rambo, 1994).

Um outro campo de interesse era a população de origem alemã do sul do Brasil, com a qual se identificava e que mereceu vários artigos e tenso acompanhamento.

Certamente isto bastaria para encher sua breve existência se fosse uma personalidade medianamente dotada. Ele não o era. No extremo oposto do cientista metódico encontramos o poeta, que escrevia poemas, poesias e cantos 
em alemão, português e latim; o orador sacro, que prendia as massas durante uma hora, sem fazer um só gesto; o escritor de histórias para a juventude que, na Alemanha, formaram coleção; o narrador fantasioso que, em dialeto hunsrück, fascinava os colonos com suas histórias escritas para calendários de grande divulgação, contando o cotidiano do campo, uma viagem à lua, ou as aventuras de um antropólogo em Marte. O interesse pelo colono, sua cultura e seu bem-estar, se manifesta em toda a sua vida e mais concretamente na revista Skt. Paulus Blatt, da qual foi redator durante muitos anos. Este mesmo interesse pela população de sua origem fê-lo organizar, junto com o Pe. Henrique Pauquet, S. J. e o Pastor Bertoldo Weber, o Socorro à Europa Faminta, que carregou navios de alimentos e roupas para a Alemanha devastada pela guerra.

Quando Balduíno Rambo se defrontava com o seu herbário, no sótão da capela do Colégio Anchieta, onde ultimamente também trabalhava e dormia, costumava dizer para si e para seus acompanhantes: "Preciso ficar atento para que o cemitério de plantas não invada e afogue a minha vida psíquica e espiritual.” Realmente isto nunca aconteceu. Para não perder a sensibilidade, todas as noites, antes de descansar, lia algum clássico grego, latino ou ocidental. E seu extensíssimo diário, escrito em alemão, revela que sua vida espiritual também não sofria nenhum dano; ele era um homem profundamente religioso e não só isto, era um místico que se comunicava com Deus e a Virgem Maria com muita intimidade.

Mais uma palavra a respeito do planejador e administrador: Para os membros de sua Ordem, que na época era pujante, planejou um instituto, que reunisse grande número de campos de saber. Junto com o Pe. Luís Gonzaga Jaeger, S. J. ele, de fato, criou o Instituto Anchietano de Pesquisas, mas a crise religiosa dos anos 60 frustrou as suas previsões; grande número dos jovens cientistas em preparação para formar seu corpo de pesquisadores abandonaram a Ordem. Quando trabalhava na Divisão de Cultura da Secretaria de Educação do Rio Grande do Sul, desenvolveu o Museu Riograndense de História Natural, foi diretor de sua revista Iheríngia, se empenhou em criar um Jardim Botânico para Porto Alegre e transformar o Taimbezinho em parque nacional.

Haveria muito mais para anotar sobre a formação, a personalidade e as atividades de Balduíno Rambo, mas é suficiente para contextualizar sua presença na Faculdade de Filosofia da URGS.

\section{Balduíno Rambo professor catedrático de Antropologia e Etnografia}

É preciso lembrar que, naquele tempo, a estrutura da Universidade era diferente. Os responsáveis pelos setores de conhecimento não eram os 
departamentos, mas as cátedras. A Congregação dos professores catedráticos e de representantes das outras categorias, que se reunia quinzenalmente, era o cérebro pensante da instituição. Nela estavam reunidos os catedráticos de todas as disciplinas ligadas à formação de professores: Letras, Filosofia, Pedagogia, Psicologia, História, Ciências Sociais, Matemática, Física, Química, História Natural... Na oportunidade da congregação se fazia intensa integração de conhecimentos, idéias e tendências. Havia talvez menos especialização, porém mais integração e o todo prevalecia facilmente sobre as partes. Também os professores representavam uma sociedade diferente e menos especializada da que temos hoje.

Balduíno Rambo era participante ativo neste corpo que constituía a universidade, mas também fazia sua preleção regular e metodicamente, como vira fazer na Europa e nas faculdades que freqüentara.

Naquele tempo dominava no Brasil uma antropologia histórica, de estilo americano, alemão ou austríaco.

Rambo era adepto da escola histórico-cultural de Wilhelm Schmidt ou, como também era chamada, da Escola de Viena. Neste tempo ela ainda era forte. O professor de História da América seguia a mesma orientação.

Como a bibliografia era quase toda em alemão e de difícil acesso, Rambo escreveu um compêndio de Etnografia Geral e um de Etnografia do Brasil, que serviam de base para o estudo dos alunos.

As aulas eram expositivas e informativas e os conceitos eram ilustrados com material etnográfico recolhido entre os Kaingang e raros artefatos arqueológicos provenientes do sul do Brasil

Rambo dava as aulas sozinho. Neste tempo ainda não havia bolsistas, eram raras as pesquisas e também as publicações. Também não fez pesquisas dentro da disciplina que lecionava. Além dos textos escolares só escreveu um pequeno relatório (Rambo, 1947) sobre duas semanas de visita aos Kaingang de Nonoai e uma conferência sobre a Arqueologia do Rio Grande do Sul (Rambo, [s.d.]).

As aulas eram bem aceitas pelos alunos, mas não despeitaram vocações. Quando fui convidado para colaborar na cadeira, em 1958, ele buscou uma implementação diferente e me encaminhou primeiro para a pesquisa arqueológica, naquele tempo entregue a poucos autodidatas inexpressivos e logo também para língua Guarani, cujo ensino rudimentar se tornara obrigatório no curso de História, junto com a Etnografia do Brasil. Para que tudo não ficasse na intenção, me pôs em contato com pessoas e lugares onde poderia conseguir aperfeiçoamento, no país e no exterior. 
Como a escola histórico-cultural de Viena estava sendo contestada e com a morte de Wilhelm Schmidt, na década de 50, foi abandonada até por seus seguidores mais imediatos, os novos auxiliares da cadeira adotaram a orientação histórica americana, que continuou em vigor nas aulas oferecidas para o curso de História até bastante tempo depois da morte de Balduíno Rambo. Ele mesmo não mudou de escola, deixando as novidades para seus jovens colaboradores. Quando Ruben George Oliven voltou de seu doutorado na Inglaterra, trouxe também a Antropologia Social, primeiro implantada no curso de Ciências Sociais e, depois, seguida, de forma geral, pela maior parte da equipe de Antropologia.

A reestruturação da universidade, com a introdução dos departamentos, o surgimento deumprograma pós-graduado, primeiro com cursos de especialização, depois com mestrado e doutorado, propiciou a situação atual, onde a Antropologia é um setor diversificado, atuante, com numerosos profissionais dedicados exclusivamente à pesquisa e ao ensino numa só universidade. A sociedade evoluiu durante este tempo, a universidade não podia deixar de acompanhar.

Balduíno Rambo era de um outro tempo: com uma formação geral imensa, enciclopédica mesmo, atuante em vários setores e muito presente na sociedade do seu tempo, não podia deixar de ser convocado, quando da fundação da Faculdade de Filosofia como cabeça pensante da Universidade. Deveria contribuir com seu conhecimento, seu prestígio e sua experiência na formação de professores e no desenvolvimento da ciência. Sua presença não se restringiu às aulas, sobre um assunto que ele poderia desenvolver, mesmo não sendo especialista no setor. No seu balanço, a presença na Universidade sempre foi considerada muito importante, mesmo que as aulas de Etnografia não ocupassem o lugar mais importante na sua agenda diária. Certamente também não era a matéria que ele mais teria gostado de ensinar. Mas ninguém lhe ofereceu a Botânica, na qual ele era realmente superior e tinha sua reflexão mais avançada.

\section{Referências}

RAMBO, B. Os índios riograndenses modernos. Província de São Pedro, n. 10, p. 81-88, 1947.

RAMBO, B. A fisionomia do Rio Grande do Sul. São Leopoldo: Unisinos, 1994.

RAMBO, B. Arqueologia riograndense. Fundamentos da Cultura Riograndense, 2. série, p. 31-44, [s.d.]. 